\title{
Management of cubital tunnel syndrome by anterior trans-muscular transposition of the ulnar nerve
}

\author{
Ahmed Shawky Ammar', Mohamed Ahmed El Tabl ${ }^{1}$ and Dalia Salah Saif ${ }^{2^{*}}$ (D)
}

\begin{abstract}
Background: Various surgical options are used for the treatment of ulnar nerve entrapment at the elbow. In this study, anterior trans-muscular transposition of the ulnar nerve was used for the treatment of cubital tunnel syndrome.

Objectives: To evaluate the surgical results of anterior trans-muscular transposition technique for the treatment of cubital tunnel syndrome with particular emphasis on clinical outcome.

Methods: Forty patients with cubital tunnel syndrome were operated using anterior trans-muscular transposition technique. Patients were classified into post-operative clinical outcome grades according to the Wilson \& Krout criteria, and they were followed up by visual analog scale (VAS), the Disability of Arm Shoulder and Hand (DASH) questionnaire, electrophysiological study, and post-operative clinical evaluation.

Results: Forty patients with cubital tunnel syndrome who underwent anterior trans-muscular transposition of the ulnar nerve show a significant clinical improvement at 24 months post-surgery regarding visual analog scale (VAS), the Disability of Arm Shoulder and Hand (DASH) questionnaire, electrophysiological study, and the Wilson \& Krout grading as $87.5 \%$ of the patients recorded excellent and good outcome.
\end{abstract}

Conclusion: Anterior transmuscular transposition of the ulnar nerve is a safe and effective treatment for ulnar nerve entrapment at the elbow.

Keywords: Ulnar nerve, Trans-muscular transposition, Cubital tunnel syndrome, DASH, VAS

\section{Introduction}

Cubital tunnel syndrome is one of the common nerve entrapment neuropathies, second to carpal tunnel syndrome. The ulnar nerve is under a considerable amount of stress due to its anatomic location and course at the elbow, from stretching and external contact [1].

The syndrome is mainly characterized by numbness of the little and ring fingers, intrinsic hand muscle atrophy, and an inability to perform fine motor activity. In some patients, pain appears at the medial aspect of the elbow and radiates to the wrist and proximal forearm [2].

Non-operative treatment is initiated when the diagnosis of ulnar entrapment at the elbow is first made

\footnotetext{
* Correspondence: Sdalia30@gmail.com

${ }^{2}$ Physical Medicine, Rheumatology and Rehabilitation, Faculty of Medicine,

Menoufia University, Shibin El Kom, Egypt

Full list of author information is available at the end of the article
}

through patient education and physical activity modifications intended to improve symptoms and to stop the progression of the disease. Patients with mild to moderate signs of compression are likely to benefit from conservative treatment [3].

Surgical treatments are recommended for patients who have not responded to non-surgical intervention that includes simple decompression, in which Osborne's band can be released using either open or endoscopic surgical methods, medial epicondylectomy, and anterior transposition of the ulnar nerve by intramuscular, submuscular, or subcutaneous placement of the nerve. Studies reported that no certain surgical method has encouraging outcomes, so in patients with an advanced stage of cubital tunnel syndrome, anterior transposition of the ulnar nerve should be considered as it can release 
the nerve and resolve the dynamic factors involved in cubital tunnel syndrome [4-8].

The purpose of this study is to evaluate the surgical results of anterior trans-muscular transposition of the ulnar nerve for the treatment of cubital tunnel syndrome with particular emphasis on clinical outcome.

\section{Methods}

Forty patients were diagnosed clinically with cubital tunnel syndrome with the presence of symptoms of numbness and paresthesia in the little finger, tingling or electric-like shock in the sensory distribution of the ulnar nerve (+ve Tinel's sign), and percussion of the cubital tunnel. Motor function was tested by checking finger abduction and flexor digitorum profundus strength for the little finger. Muscle wasting or atrophy was examined at first dorsal interosseous muscle. All patients were collected in the period from October 2014 to December 2016 from the outpatient clinic of Neurosurgery and Physical Medicine, Rheumatology and Rehabilitation Department at Menoufia University hospitals. The study included both sexes. Their age ranged from 28 to 48 years. All patients were from the Menoufia governorate. The research protocol was approved by the ethical committee of the Faculty of Medicine, Menoufia University. An informed written consent was obtained from each patient.

Other causes of upper limb pain and numbness are ulnar nerve entrapment against Guyon's canal and a double crush lesion, such as cervical spondylopathy or thoracic outlet syndrome; patients with revision surgery and those with any systemic illness that causes polyneuropathy were excluded.

All patients were subjected to demographic data recording, history taking, and clinical examination including clinical grading by McGowan preoperative grading system [9] in which patients of the study group were classified into three clinical grades: grade I, had no muscle weakness; grade II, had muscle weakness but no atrophy; and grade III, had muscle wasting. Assessment of pain regarding visual analog scale (VAS) $[10,11]$ and assessment of function via the Disabilities of the Arm, Shoulder and Hand (DASH) questionnaire that is a selfadministered region-specific outcome instrument to measure upper-extremity disability and symptoms [12] were performed. The DASH consists mainly of a 30item disability/symptom scale, scored 0 (no disability) to 100 , and electrophysiological study was used. All patients were subjected to examinations of motor conduction velocity (MCV) $2 \mathrm{~cm}$ below the elbow (MCV1) and $2 \mathrm{~cm}$ above the elbow (MCV2). We consider conduction block or slowing more than $10-11 \mathrm{~m} / \mathrm{s}$ across the elbow compared with the forearm segment in the flexed elbow position significant for ulnar neuropathy at the elbow.
Postoperatively, all patients were graded according to the Wilson \& Krout criteria [13]: patients with minimal sensory and motor deficits and no tenderness at the incision site were graded excellent, patients with a mild deficit but occasional ache or tenderness at the incision or osteotomy site were graded good, patients with an improved but persistent deficit were fair, and those with no improvement or a worsened condition were poor [13].

All this parameters were performed for all patients before and at 24 months post-surgery for follow-up.

\section{Surgical technique}

All patients were operated under general anesthesia. Patient is placed in supine position, arm extended, abducted $90^{\circ}$ at shoulder, and the palm is supinated. Eight to $10 \mathrm{~cm}$ longitudinal slightly curved incision is made just posterior to medial epicondyle; soft tissue is dissected to identify branches of medial antibrachial cutaneous nerve (MACN) branches that should be preserved to avoid painful neuroma. If a branch of MACN is inadvertently injured, the distal end is cauterized and transposed to the muscle bed away from the surgical scar. After exposure of flexor pronator mass, dissection continues proximally and distally. The ulnar nerve is better found posterior to the medial intermuscular septum which is splitted, then ulnar nerve is followed, and Osborn's ligament is cut to expose the ulnar nerve in cubital tunnel. The nerve is followed distally to completely freeing it between the two heads of flexor carpi ulnaris (FCU) muscle. Motor branches from ulnar nerve to FCU muscle should be preserved and neurolysed to facilitate ulnae nerve transposition without kinking points.

A step lengthening incision is made in the facia of the flexor pronator mass, and facial flaps are elevated. A transmuscular tunnel is created through flexor pronator mass. The ulnar nerve is transposed anteriorly within the transmuscular tunnel without any acute angles or kinking points. The ends of the facial flaps are then loosely re-approximated over the ulnar nerve keeping the nerve in its new place. Good hemostasis is achieved through closure of the wound in layers with closed suction drain. Bandage is used to keep the elbow flexed at $90^{\circ}$, forearm pronated, wrist is kept in neutral position, and limb is supported by arm to neck sling. Drain is removed when the output is less than $30 \mathrm{ml}$ in $24 \mathrm{~h}$. Patients are instructed for an early range of motion for hand, wrist, elbow, and shoulder.

The follow-up was done at 24 months post-surgery regarding clinical and electrophysiologic improvement.

\section{Results}

Forty cases of cubital tunnel syndrome were operated; $23(57.5 \%)$ were males and 17 (42.5\%) were females. Age 
ranged between 28 and 48 years with a mean age of 38.5 \pm 10.00 years (Table 1 ) (Additional file 1 ).

In the present study, there was a statically significant improvement of pain in the distribution of ulnar nerve at the medial aspects of the forearm, hand, and the little finger and statically significant improvement of function regarding DASH questionnaire in patients of the study group at 24 months post-surgery compared to pre-operative parameters, $p=0.001$ (Table 2) (Additional file 2).

Our study revealed a statically significant improvement of motor nerve conduction velocity of the ulnar nerve across the elbow in the patients of the study group after surgery compared to pre-operative measures as the conduction velocity difference between below elbow and above elbow was $6.38 \pm 2.22$ and after surgery less than 11, that means no conduction block across elbow after surgical procedure (Table 3) (Additional file 3) (Figs. 1 and 2).

There was an obviously significant clinical improvement in the patients of the study group at 24 months post-surgery regarding Wilson \& Krout grading, as 65\% of patients recorded excellent grade, $22.5 \%$ good, and $12.5 \%$ fair, compared to pre-operative results regarding McGowan grading systems, as pre-operative data was $20 \%$ of patients were G1 (with only sensory manifestations), $67.5 \%$ of patients were G2 (with muscle weakness), and $12.5 \%$ of patients were G3 (with muscle wasting) (Table 4) (Additional file 4).

\section{Discussion}

The purpose of this study is to evaluate the surgical results of anterior trans-muscular transposition of the ulnar nerve for the treatment of cubital tunnel syndrome with particular emphasis on clinical outcome.

In the present study, there was a statically significant improvement of pain in the distribution of ulnar nerve at the medial aspects of the forearm, hand, and the little finger and statically significant improvement of function regarding the DASH questionnaire in patients of the study group at 24 months post-surgery compared to the preoperative parameters.

Our study revealed a statically significant improvement of conduction velocity of ulnar nerve across elbow in the

Table 1 Demographic data among patients of the study group

\begin{tabular}{lll}
\hline & Patient group $(M \pm$ SD $)$ \\
\hline Age & $38.53 \pm 10.00$ \\
Sex & No. & $\%$ \\
Male & 23 & 57.5 \\
Female & 17 & 42.5 \\
\hline
\end{tabular}

This table shows the age and sex among patients of the study group
Table 2 Visual analog scale (VAS) and Disability of Arm, Shoulder and Hand (DASH) questionnaire before and after surgery among patients of the study group

\begin{tabular}{lllll}
\hline Group & Pre-op $(M \pm$ SD $)$ & Post-op $(M \pm$ SD $)$ & $t$ test & $P$ value \\
\hline DASH & $45.82 \pm 7.09$ & $14.97 \pm 2.78$ & 32.3 & 0.001 \\
VAS & $8.28 \pm 0.71$ & $2.57 \pm 3.4$ & 10.66 & 0.001 \\
\hline
\end{tabular}

This table shows statistically significant improvement of pain and function of the ulnar nerve of the patients of the study group before and after surgery regarding VAS and DASH

patients of the study group at 24 months after surgery compared to preoperative measures.

There was a significant clinical improvement of patients of the study group at 24 months post-surgery regarding the Wilson \& Krout grading as $87.5 \%$ of the patients recorded excellent and good.

Our results are consistent with the Frantz et al. [14] study as they reported that the ulnar nerve anterior transmuscular transposition in the lateral decubitus position is a good surgical option for primary or recurrent cubital tunnel syndrome and remains the preferred procedure. The overall patient satisfaction rate was $92 \%$, with statistically significant improvements in ulnar sensation and intrinsic strength at short- and long-term follow-up.

In the same line, Novak [15] and his colleague reported that $61 \%$ of patients who underwent anterior trans-muscular transposition of the ulnar nerve procedures reported improvement. Postoperative symptoms were significantly less than those preoperatively regarding pain, cold sensitivity, tingling, and numbness, $p=$ 0.08 . In $51 \%$ of the cases, patients reported normal sensation, and in $45 \%$ of cases, patients reported normal strength.

Stuebe [16] and his colleague also reported that the long-term patient follow-up suggests that the ulnar nerve transposition can facilitate the return of intrinsic muscle mass and function among patients with cubital tunnel syndrome.

Huang et al. [2] and his colleague reported that the anterior subcutaneous transposition of the ulnar nerve is effective and safe for the treatment of moderate to

Table 3 Motor nerve conduction velocity (1) and (2) before and after surgery of the patients of the study group

\begin{tabular}{lllll}
\hline & $\begin{array}{l}\text { Pre-op }(M \pm \\
\text { SD) }\end{array}$ & $\begin{array}{l}\text { Post-op }(M \pm \\
\text { SD) }\end{array}$ & $t$ test & $P$ value \\
\hline MNCV 1 & $57.65 \pm 5.58$ & $51.75 \pm 4.23$ & 5.77 & 0.001 \\
MNCV 2 & $44.85 \pm 2.6$ & $54.32 \pm 1.86$ & 18.44 & 0.001 \\
MNCV difference across & $15.4 \pm 1.69$ & $5.95 \pm 1.28$ & 26.3 & 0.001 \\
elbow & & & & \\
\hline
\end{tabular}

This table shows statically significant differences (improvement) of motor nerve conduction velocity of ulnar nerve across elbow of the patients of the study group before and after surgery 


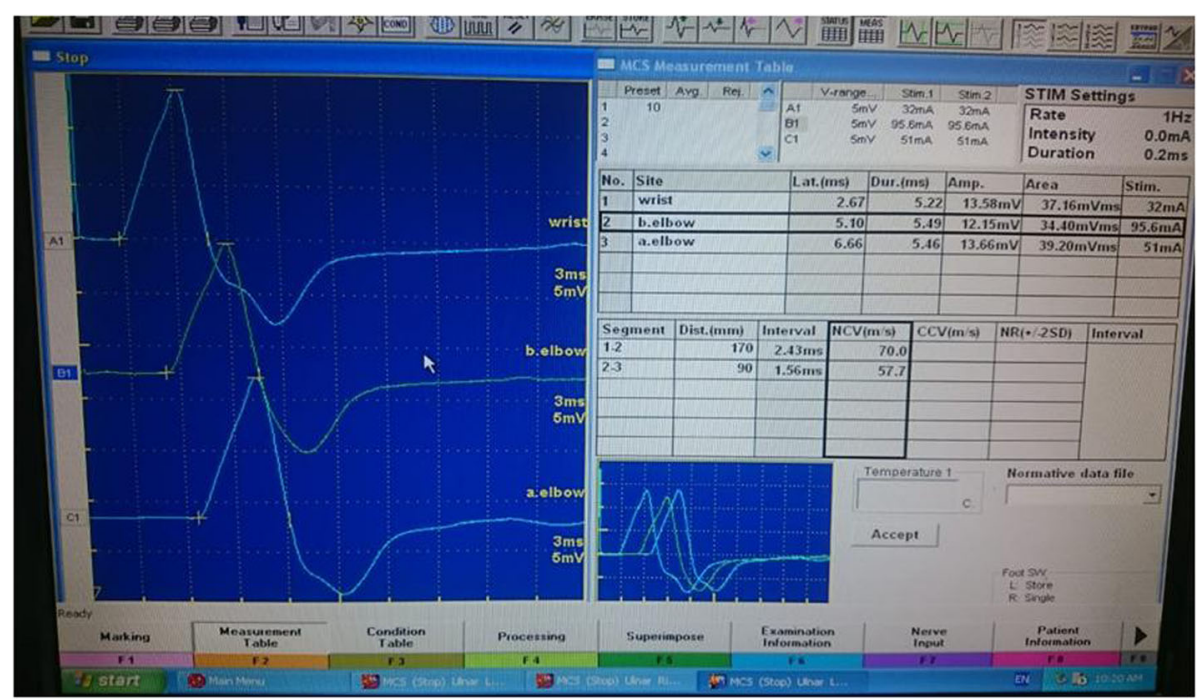

Fig. 1 MNCS of the ulnar nerve of the patients of the study group before surgery

severe cubital tunnel syndrome, as it can lead to good outcomes regarding the pain score (VAS) and the disability score (DASH) that were reduced significantly. Also, they concluded that both preoperative and postoperative electrophysiological values help predict the functional outcome of surgery and that most patients achieved post-surgical excellent/good outcomes with low complication rate.

On the other hand, Capo and his team [17] in their study compared subcutaneous anterior transposition versus decompression and medial epicondylectomy for the treatment of cubital tunnel syndrome, and they reported that the results do not indicate a difference between the outcomes of the patients undergoing either of the procedures, and as epicondylectomy is less technically demanding, with less soft tissue dissection of the nerve, it may be preferred over ulnar transposition.

Macadam et al. [18] in their study also compared subcutaneous and submuscular transposition of the ulnar nerve for cubital tunnel syndrome, and they found no statistically significant difference, but rather a trend toward an improved clinical outcome with transposition of the ulnar nerve as opposed to simple decompression.

Finally, the results of our study are based on an objective and subjective measures for evaluations of disease severity and surgical outcome, with average sample size and long-term follow-up period, without any complications, the surgical procedure conducted by one doctor, and with a single technique for more accurate results compared to other studies.

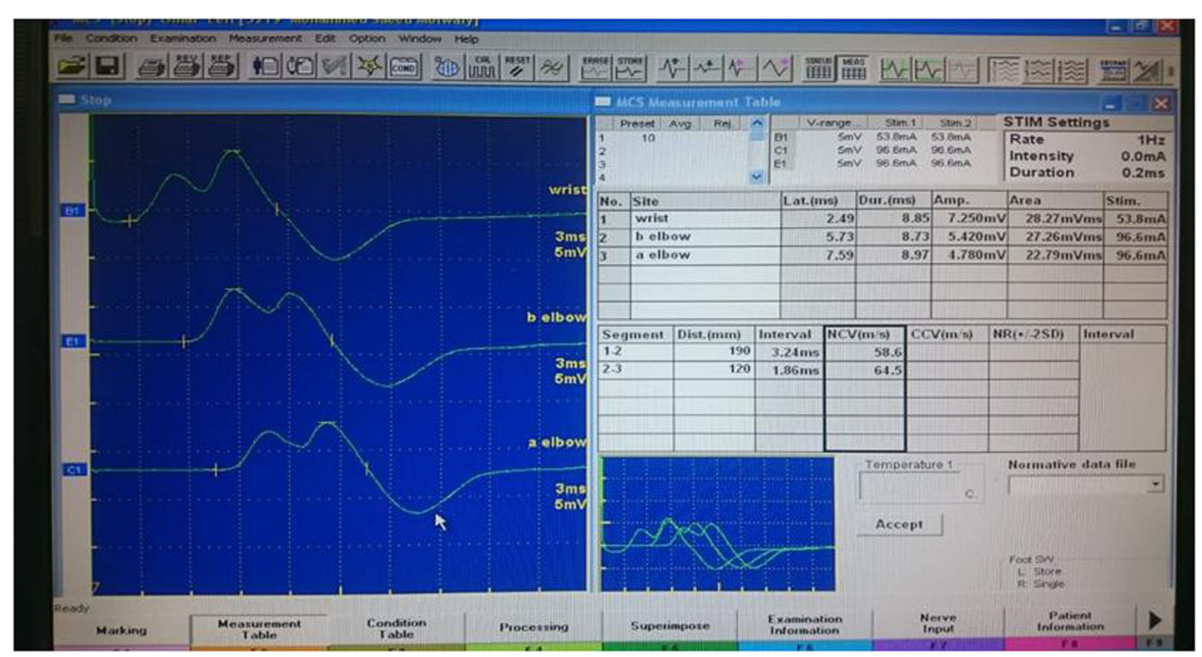

Fig. 2 MNCS of the ulnar nerve of the patients of the study group at 24 months post-surgery 
Table 4 Clinical evaluation pre- and post-surgery regarding McGowan and Wilson \& Krout grading among the patients of the study group

\begin{tabular}{llllll}
\hline Grading & \multicolumn{2}{l}{ Pre-op } & McGowan & & \multicolumn{2}{l}{ Post-op Wilson \& Krout } \\
\cline { 2 - 3 } & No. & $\%$ & & No. & $\%$ \\
\hline G1 & 8 & 20 & & 26 & 65 \\
G2 & 27 & 67.5 & & 9 & 22.5 \\
G3 & 5 & 12.5 & & 5 & 12.5 \\
\hline
\end{tabular}

This table shows an obvious significant clinical improvement of the patients of the study group at 24 months post-surgery regarding Wilson \& Krout compared to pre-operative results regarding McGowan grading systems

\section{Conclusion}

We have found that anterior trans-muscular transposition of the ulnar nerve is a safe and effective treatment for ulnar nerve entrapment at the elbow. When performed by trained surgeons, excellent or good results are achievable.

\section{Supplementary information}

Supplementary information accompanies this paper at https://doi.org/10. 1186/s41984-019-0067-2.

Additional file 1. Graph 1. Sex amongg patients of the study group.

Additional file 2. Graph 2. Assessment of pain and function of ulnar nerve in patients before and after surgery regarding VAS and DASH.

Additional file 3. Graph 3. Motor nerve conduction velocity of ulnar nerve across elbow in the patients before and after surgery.

Additional file 4. Graph 4. Post-operative regarding Wilson \& Krout compared to pre-operative results regarding McGowan grading systems.

\section{Abbreviations}

CV: Conduction velocity; DASH: Disabilities of the Arm, Shoulder and Hand questionnaire; FCU: Flexor carpi ulnaris; MACN: Medial antebrachial cutaneous nerve; MNCS: Motor nerve conduction study; MNCV difference: Motor nerve conduction study difference; NCS: Nerve conduction study; SD: Standard deviation; VAS: Visual analog scale

\section{Acknowledgements}

Not applicable.

\section{Authors' contributions}

ASA: Concepts, Design and Definition of intellectual content. MAET: Literature search. MAET and DSS: Clinical studies and Experimental studies. ASA and DSS: Data acquisition. ASA and MAET: Statistical analysis. DSS: Manuscript editing. ASA and MAET: Manuscript review and Guarantor. All authors read and approved the final manuscript.

\section{Funding}

Not applicable.

\section{Availability of data and materials}

All data generated or analyzed during this study are included in this published article (and its supplementary information files).

\section{Ethics approval and consent to participate}

The research protocol was approved by the ethical committee of the Faculty of Medicine, Menoufia University, in its monthly session dated 24 September 2014. An informed written consent was obtained from each patient.

\section{Consent for publication}

The manuscript does not include details, images, or videos relating to individual participants.

\section{Competing interests}

The authors declare that they have no competing interests.

\section{Author details}

${ }^{1}$ Neurosurgery Faculty of Medicine, Menoufia University, Shibin El Kom, Egypt. ${ }^{2}$ Physical Medicine, Rheumatology and Rehabilitation, Faculty of Medicine, Menoufia University, Shibin El Kom, Egypt.

Received: 19 April 2019 Accepted: 16 October 2019

Published online: 23 December 2019

\section{References}

1. Glowacki KA, Weiss AP. Anterior intramuscular transposition of the ulnar nerve for cubital tunnel syndrome. J Shoulder Elbow Surg. 1997;6:89-96.

2. Huang W, Zhang P, Peng Z, Feng Xue, Wang T, M.D.* and Jiang B, M.D., Ph. D. Anterior subcutaneous transposition of the ulnar nerve improves neurological function in patients with cubital tunnel syndrome. Neural Regen Res. 2015 Oct; 10(10): 1690-1695.

3. James BL, Suzan EM. Ulnar nerve entrapment at the elbow. In: Winn HR, editor. Youmans Neurological Surgery, vol. 7. Philadelphia: W.B Saunders; 2004. p. 3897-920

4. Bolster MA, Zophel OT, van den Heuvel ER, Ruettermann M. Cubital tunnel syndrome: a comparison of an endoscopic technique with a minimal invasive open technique. J Hand Surg Eur Vol. 2013;39:621-5.

5. Macadam SA, Gandhi R, Bezuhly M, Lefaivre KA. Simple decompression versus anterior subcutaneous and submuscular transposition of the ulnar nerve for cubital tunnel syndrome: a meta-analysis. J Hand Surg Am. 2008; 33:1311-4.

6. Zlowodzki M, Chan S, Bhandari M, Kalliainen L, Schubert W. Anterior transposition compared with simple decompression for treatment of cubital tunnel syndrome. A meta-analysis of randomized, controlled trials. J Bone Joint Surg Am. 2007;9:2591-8.

7. Zarezadeh A, Shemshaki H, Nourbakhsh M, Etemadifar MR, Moeini M, Mazoochian F. Comparison of anterior subcutaneous and submuscular transposition of ulnar nerve in treatment of cubital tunnel syndrome: a prospective randomized trial. J Res Med Sci. 2012;17:745-9.

8. Bacle $G$, Marteau E, Freslon M, Desmoineaux $P$, Saint-Cast $Y$, Lancigu $R$, Kerjean Y, Vernet E, Fournier J, Corcia P, Le Nen D, Rabarin F, Laulan J. Cubital tunnel syndrome: comparative results of a multicenter study of 4 surgical techniques with a mean follow-up of 92 months. Orthop Traumatol Surg Res. 2014;100:S205-8.

9. McGowan AJ. The results of transposition of ulnar nerve for traumatic ulnar neuritis. J Bone Joint Surg Br. 1950;32:293-301.

10. Gould D, Kelly D, Goldstone L, Gammon J. Visual analogue scale (VAS). J ClinNurs. 2001;10:697-706

11. Dauphin P, AGuillemin F, Virion JMand Briançon S. Bias and precision in visual analogue scales: a randomized controlled trial. Am J Epidemiol. 1999; 15:150:1117-27.

12. Gummesson $\mathrm{C}$, Atroshi I, Ekdahl C. The disabilities of the arm, shoulder and hand (DASH) outcome questionnaire: longitudinal construct validity and measuring self-rated health change after surgery. BMC Musculoskeletal Disorders. 2003:4:11

13. Schnabl SM, Kisslinger F, Schramm A, Dragu A, Kneser U, Unglaub F, Horch RE. Subjective outcome, neurophysiological investigations, postoperative complications and recurrence rate of partial medial epicondylectomy in cubital tunnel syndrome. Arch Orthop Trauma Surg. 2011;131:1027-33.

14. Frantz LM, Adams JM, Granberry GS, Johnson SM, Hearon BF Outcomes of ulnar nerve anterior transmuscular transposition and significance of ulnar nerve instability in cubital tunnel syndrome. J Shoulder Elbow Surg. 2019 2018.11.054.

15. Novak CB ${ }^{1}$, Mackinnon SE, Stuebe AM. Patient self-reported outcome after ulnar nerve transposition. Ann Plast Surg. 2002 ;48(3):274-280.

16. Stuebe AM, Novak CB, Mackinnon SE. Recovery of ulnar innervated intrinsic muscles following anterior transposition of the ulnar nerve. Can J Plast Surg. 2001;9(1):25-8.

17. Capo $\mathrm{JT}^{1}$, Jacob G, Maurer RJ, Nourbakhsh A, Preston JS. Subcutaneous anterior transposition versus decompression and medial epicondylectomy 
for the treatment of cubital tunnel syndrome. Orthopedics. 2011 .9;34(11): e713-e717. doi: https://doi.org/10.3928/01477447-20110922-18.

18. Sh M, Gandhi R, Lefaivre KA, Bezuhly M. Simple decompression versus anterior subcutaneous and submuscular transposition of the ulnar nerve for cubital tunnel syndrome: a meta-analysis. The Journal of hand surgery. 2008; 33(8):1314.e1 12

\section{Publisher's Note}

Springer Nature remains neutral with regard to jurisdictional claims in published maps and institutional affiliations.

\section{Submit your manuscript to a SpringerOpen ${ }^{\circ}$ journal and benefit from:}

- Convenient online submission

- Rigorous peer review

- Open access: articles freely available online

- High visibility within the field

- Retaining the copyright to your article

Submit your next manuscript at $\boldsymbol{\wedge}$ springeropen.com 